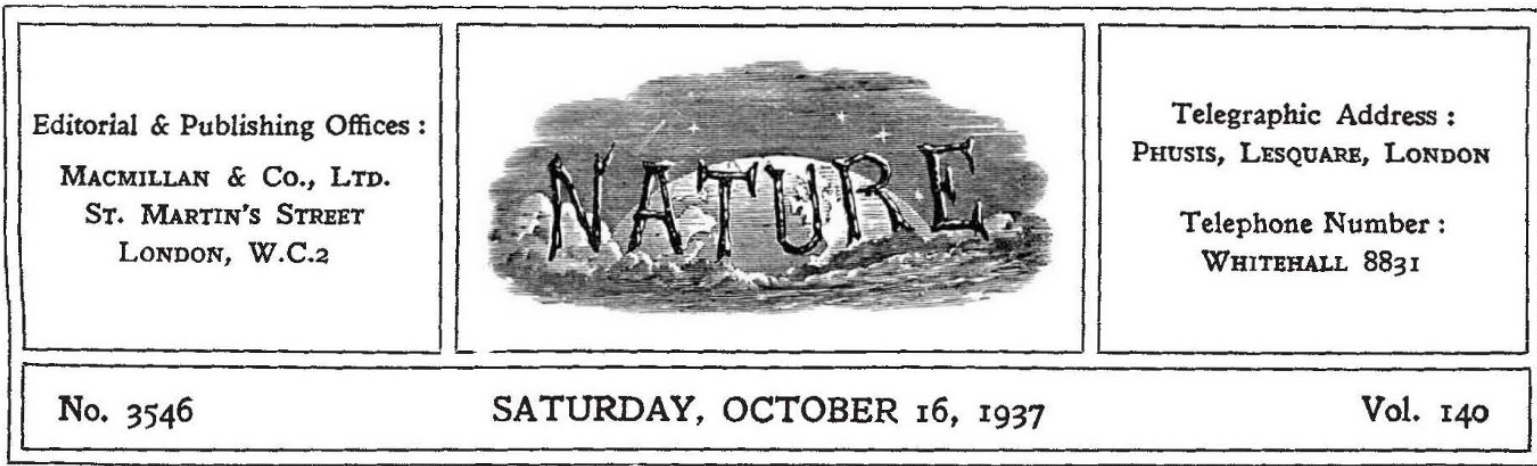

\title{
Physiology in General Education
}

$\mathrm{U}^{\mathrm{N}}$ NTIL within very recent times, the study of the human body was practically solely the concern of physiological departments in medical schools. Undergraduates outside the medical curriculum had no opportunity of studying human physiology, and the people of Great Britain as a whole seemed well content to leave the control of their lives with respect to health and disease to the guidance of the medical profession. Thus, when 'science' was first introduced into the schools, educationists turned to chemistry and to physics, and, even to-day, such biology as is taught in schools deals almost wholly with plants and lower animals. That "the proper study of mankind is man" was the keynote of the discussion on "Physiology in General Education" in Section I (Physiology) of the British Association during the recent Nottingham meeting.

All the speakers in the discussions were unanimous that this loss of contact between human physiology and general education is a misfortune, not only for a modern democracy but also for physiology itself. Experimental psychology, which, as practised today, is but a branch of experimental physiology, has hived off from physiology, largely due to the absorption of physiologists in the needs of medical students. Biochemistry is shifting its camp from physiology to organic chemistry probably for the same reason.

This unfortunate lack of facility for study of human physiology in British universities reacts on school education and on adult education. The future school teacher has to rely almost wholly on training centres for instruction in human physiology and hygiene. These facilities, although admirable in many cases, are not to be compared with those already in being in our universities.
The end-result is that the content of physiological knowledge of the 'man in the street', and even of his legislators, is at a dangerously low level.

Moreover, whenever there is loss of contact between the practising scientific investigator and the public, there arises inevitably the risk of loss of understanding and of sympathy. The agitation against vivisection is very largely due to ignorance, on the part of the public, of physiological practice, and of the vital part played by physiological research in everyday life.

But the physiologist is not the only sufferer. From the cradle-and even earlier-to the grave, physiological first principles affect our health and well-being. In a modern civilized community it is no longer possible to rely solely on the bounty of Nature for our food and proper nourishment, or on our natural instincts for the conduct of our own and others' lives. The public, crassly ignorant for the most part of the elementary facts about the human body, ignores the simplest dietetic principles, falls victim to the specious advertisements of the vendors of fortified foodstuffs and of quack nostrums, and blindly follows the fatuous dictates of the latest fashion. Moreover, as one speaker in the discussion at Nottingham emphasized, all propaganda and legislation in the interests of public health must of necessity lose the greater part of their effectiveness if the public is incapable of appreciating the significance of, and reasons for, such activities.

After the comments made by Mr. H. G. Wells upon the teaching profession at this meeting of the British Association, it might have been expected that school teachers would not be in a mood to suffer tamely further suggestions from amateur, as 
distinct from professional, educationists. Nevertheless, there was no protest at the suggestion that, to make way for the necessary instruction in human physiology, either some subject at present in the school curriculum would have to be dropped or a compromise effected by using human physiology as an introduction to, and a vehicle for, the teaching of general biology. It was pointed out that it is a sound pedagogic principle to proceed from the known, or at least the familiar, to the unknown. Study of the human body and of its functions is an admirable introduction to the study of other forms of life and of biological principles in general. Moreover, human physiology gives great scope for practical work with the minimum of apparatus; in short, it is good science, good biology and admirably adapted to school instruction.

Although the day is long past when all mention of human structure and of human function was taboo, yet some fear was expressed during the discussion that teaching of human physiology might lead to unhealthy self-consciousness and introspection on the part of the pupils. The general opinion seemed to be, however, that such a danger is more likely to arise in the course of unofficial health talks conducted by enthusiastic but unskilled instructors than in routine school teaching. Indeed, Prof. Winifred Cullis, from her wide experience, believes that school instruction in human physiology, so far from inducing morbid preoccupation with the functions of the body, would rather tend to ventilate and bring into the unemotional atmosphere of the schoolroom. and thus into proper perspective, many matters which, even to-day, the modern child is shy of discussing with its elders.

The meeting was a very large one for a purely sectional discussion, and the fact that the practising physiologists were in an extremely small minority is an indication of the widespread interest the subject aroused. From every point of view it was unfortunate that a joint discussion with Section L (Educational Science) could not be arranged, for the time has clearly arrived when the place of physiology or human biology in school science courses must be given serious attention.

\section{Registration and Privilege}

$\mathrm{T}$ 'HE extent to which the principles of 'free trade' are inbred in the people of Great Britain is well illustrated by the statutory provisions governing the registration of medical practitioners and pharmacists. For both professions the State establishes standards of education and examination, with a statutory register of those who reach them. To permit the public to differentiate between the qualified and the unqualified practitioner, the use of titles implying registration is prohibited and the signing of death certificates, the sale of poisons, and other minor matters are controlled. But in both medicine and pharmacy the practice of the calling by unregistered men has few statutory limitations.

By way of contrast, the lawyer is well protected. It is a statutory offence for a layman to practise as a solicitor, and in the High Court His Majesty's judges will neither see nor hear the advocate who is not a barrister. Accountants and architects have certain titles reserved to them, but few other statutory privileges. The high-water mark of protection for a calling is probably that given to dentists, the Dentists Act of 1921 making it an offence for the unregistered to "practise dentistry".

Many attempts have been made in recent years to persuade Parliament to regulate the practitioners of a calling by means of a statutory register and to provide statutory privileges for the registered. The destruction of the Osteopaths Bill exemplifies the fate of such attempts. It is in the totalitarian States that there will be found the modern examples of restrictive legislation for the control and benefit of individual callings and their protection from competition. Whether the price to be paid compensates for the advantages, even to the sheltered practitioner himself, is a question the answer to which depends upon the temperament of the individual. The majority of the people of Great Britain are not temperamentally inclined to a régime of professional corporations, even for personal benefits, and that spirit is reflected in the attitude of Parliament towards Bills proposing to accord privileges to closed professions.

Nevertheless, there is a price to be paid for freedom. In the medical and pharmaceutical fields the price is the exploitation of the public by the 